Article

\title{
How to Adopt BIM in the Building Construction Sector across Greece?
}

\author{
Efthimios Bakogiannis ${ }^{1}$, Kalliopi Papadaki ${ }^{2}$, Charalampos Kyriakidis ${ }^{1, *}$ and Chryssy Potsiou ${ }^{1}$ \\ 1 Department of Geography and Regional Planning, School of Rural and Surveying Engineering, National \\ Technical University of Athens (NTUA), 9, H. Polytechniou Str., Zographou Campus, 15780 Athens, Greece; \\ ebako@mail.ntua.gr (E.B.); chryssyp@survey.ntua.gr (C.P.) \\ 2 Ministry of Environment and Energy, 17 Amaliados Str., 11523 Athens, Greece; arc.kalliopi@gmail.com \\ * Correspondence: kyriakidisharry@gmail.com; Tel.: +30-210-772-11-53
}

Received: 21 January 2020; Accepted: 11 February 2020; Published: 18 February 2020

check for updates

\begin{abstract}
The construction sector is of strategic importance for the European Commission. This is the reason why there is a special interest in the development of this sector which is attempting to transform into a more sustainable one in order to face various challenges. In this context, European Directive 2014/24/EU brings to the foreground of the European institutional framework the term building information modelling (BIM), that it is widely used in many countries across Europe. In Greece, the situation seems to be different, not only because it has not been applied in practice but also because of some special features of the way the construction sector functions. This paper presents the BIM use-level in Greece and the way with which it could be better integrated in the construction sector. Through this review we make a brief assessment of the strategy developed in order for the BIM to be integrated in Greek building procedures. Furthermore, we focus on specific issues, like the extended informal housing phenomenon, and on factors that cannot easily be standardized that create problems in BIM use. Finally, through an initial market analysis we underline the role of academic institutions for integrating BIM across Greece.
\end{abstract}

Keywords: BIM; Greece; task group; policies; public sector

\section{Introduction}

The construction sector is of strategic importance for the European Commission (EC) [1] as it creates and maintains the buildings and infrastructure necessary for other economic sectors [2] and provides the base for all the activities that take place in the European Union (EU) from the economic and social point of view. It represents $9 \%$ of the gross domestic product (GDP) of the EU-28 [3] and is the largest industrial employer in Europe, despite the declining course observed in the beginning of the 2010s, because of the economic crisis (see in [4]). Over 43.6 million workers in the EU depend directly or indirectly on the construction sector, a fact that underlines its dynamics; $40 \%-45 \%$ of energy consumption in Europe comes from buildings ([5,6]), while $5 \%-10 \%$ is used for processing and transport of products and accessories of the construction sector.

From the above it is clear that, as much in the medium term as long term, the construction sector and the infrastructure sector, in general, must adapt to the directions of sustainable strategies aiming at the delimitation of a series of environmental problems. Indeed, the future strategy for competitiveness in the construction sector is called upon to be environmentally sustainable and, in parallel, must focus on the social challenges formed on the European and world level. For this reason, the EU strategy for the sustainable competitiveness of the construction sector focuses even on employment and market access [1], which constitute important parameters for the reinforcement of EU citizens' quality life. 
Such a direction seems to be the continuation of the Horizon 2020 Strategy directions that aimed at the creation of healthy, safe, viable and intelligent infrastructure [1].

In this context, European Directive 2014/24/EU [7] brings to the foreground of the European institutional framework the term building information modelling (BIM). The term is mentioned in article No. 22 of the Directive where it is noted that in the framework of signing public works contracts and the invitation to tenders for relative studies, the member states must include the use of specialized electronic modelling tools for building construction information or similar means. Even if BIM is widely used in countries like France, United Kingdom and Germany [8], things in Greece are very different. This paper presents the BIM use level in Greece and the way with which it could be better integrated in the construction sector. The aim of the work is to present an overview of the situation and to make a brief assessment on the proposals developed for the better adoption of the tool in Greece, taking into consideration the European experience (Section 3). Previously (Section 2), a literature review is undertaken where the tool is described along with the advantages of its use. The results that arise (Section 4) permit a review regarding the actions taking place and programmed in the immediate future.

\section{Building Information Modelling (BIM) in Promoting Sustainable Development: A Brief Literature Review}

BIM became a popular acronym in the last decade [9], although it emerged as a concept in the late 1970s [10], after years of research in order for the components and repercussions of building product models to be investigated [11]. It is a process that uses computer technology $[12,13]$ to stimulate the performance of a building, during the whole building life-cycle, and provide a communication channel between architects, the construction team and the client [13] that may even be the public sector.

According to the National BIM Standards (NBIMS) Committee [14], "a BIM is a digital representation of physical and functional characteristics of a facility. As such it serves as a shared knowledge resource for information about a facility forming a reliable basis for decisions during its life-cycle from inception onward". The above definition clearly depicts BIM as an operational methodology aiming at decision making [15] and not a designing software as it is often, incorrectly, understood [16]. Its complete application includes information and data for the whole building from masonry to structural elements to engineering systems, material measurements and suppliers data, for each specific project.

The methodology could be applied not only in design but also during the study phase $[18,19]$. Its use and advantages extend to all the phases of the project life circle [20] (Figure 1), supporting services such as cost management, project management, constructability and operations management. The final product of such holistic procedure is not simply a better building or a 3D model on the computer [21]. The basic idea of the methodology is the exact, complete planning, study and depicting construction of the building such as it will be built, before it is build, aiming to solve the problems that may arise along the way. Through the production of a model, all the information relating to it can be connected to the depiction of the building, namely, all its structural elements, the construction materials, the stationary equipment, the special constructions, the mobile equipment, etc., along with the respective crews, and companies connected to them [22]. BIM presents each detail and constitutes an open digital archive for the "reading" of the building, which can be informed and updated. For this reason, in some countries, the same holistic study and construction methodology is called virtual design and construction (VDC). 


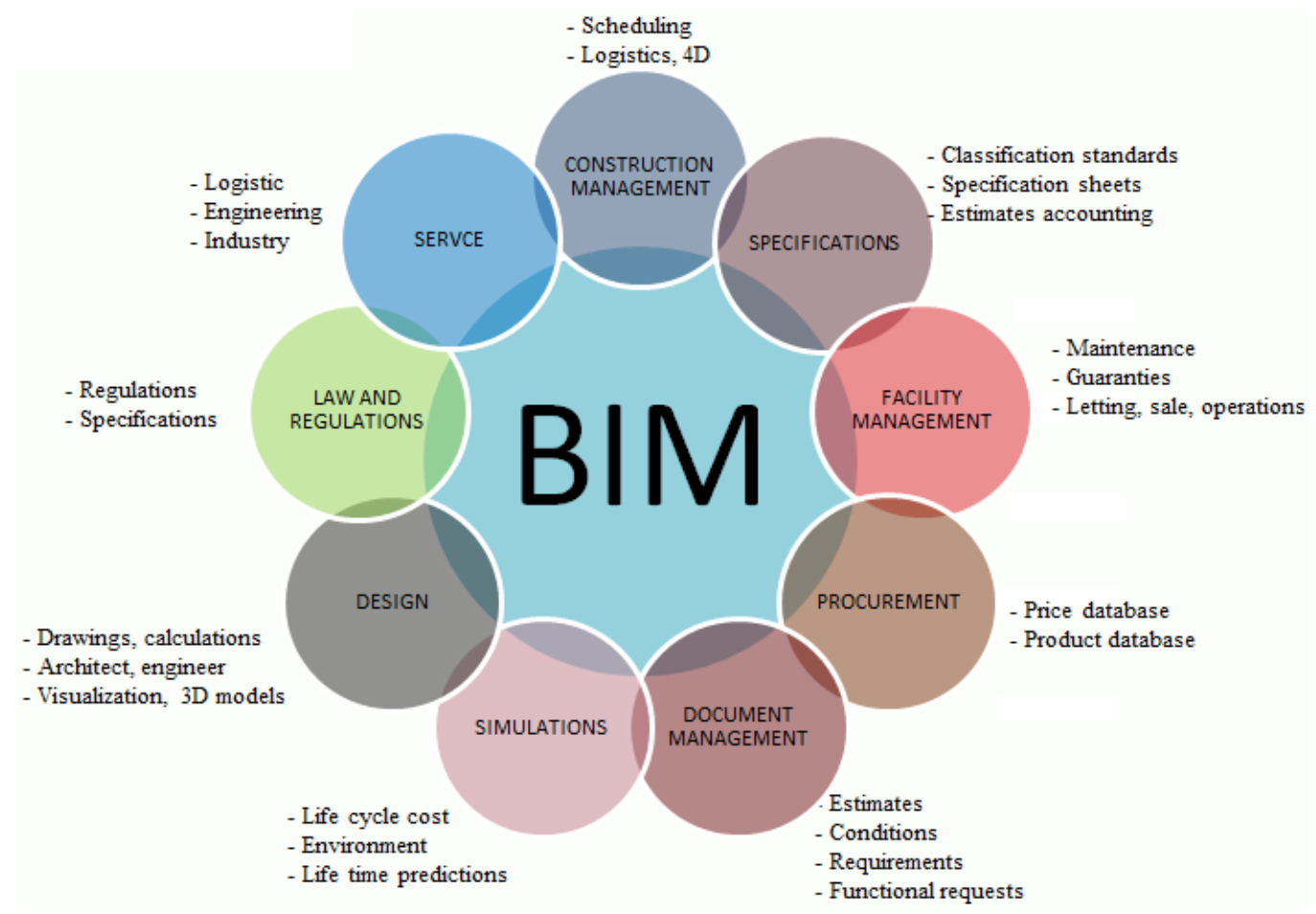

Figure 1. The use of BIM during the whole life cycle of a building. Source: [17].

Regarding BIM's benefits, these mainly refer to the following points [23]:

- Improved efficiency in the study and construction because of the easy availability of information.

- Immediate renewal and greater accuracy of plans.

- Greater measurement, cost accuracy and better study quality.

- Energy efficiency study very quickly and in an early stage of the study procedure.

- Faster project delivery.

- Constructability control leading to risk and cost decrease.

Despite the advantages presented above, BIM's real value is related to the potential capacities among all the implicated professionals as well as between professionals and clients. With the application of BIM in practice, procedures and analyses are generally facilitated, which up until now were complicated, time consuming and expensive during their effectuation.

Finally, the importance of the use of BIM in the attainment of sustainable development on two scales must be underlined: The microscale and the macroscale. In particular:

- In the microscale, namely on building level, the use of BIM permits the quick and easy extraction of results (integrated outputs) referring to the energy behaviour of each building. At the same time, there is the possibility of strategy selection for resource saving (integrated design and design optimization), resulting in the optimization of planning in order to achieve the "green goals" of each project. Actually, through BIM it is possible to draw measurements of energy output in real time (performance monitoring), thus having the possibility to compare between evaluations during the study procedure and the operation phase, in order to promote the optimization of the tools. So it is ascertained that even if the possibilities and applications of BIM on "green planning" have not reached their optimal level yet, a wide range of building industry professionals use BIM for delivering green projects $[15,24,25]$.

- In macroscale, namely, the level of neighborhood or town, the use of BIM permits the optimization of the planning and management of urban areas, in the following ways: (b1) Easy and quick evaluation of the characteristics of all the buildings regarding a series of structural and town 
planning characteristics (land use, building height, construction period, architectural morphology, construction and housing material, existence of a yard, etc.). In this way, it is possible to immediately extract results regarding the character of each area and evaluate the value of each unit of real estate. This fact considerably decreases the time of analytical process, which consists the first stage of urban planning procedures. (b2) The possibility of calculation of the energy efficiency of the building overall, for an integral energy planning to be feasible on a wider scale. The specific parameter seems to be able to function also as an efficiency indicator of specific policies or urban planning interventions such as the increase of green surface and water on cities, terrace planting and the exploitation of different structural materials aiming to improve the cities bioclimatic design.

The above advantages of BIM exploitation constitute reasons for which they are promoted on a European level and for which there is great interest for their application in Greece and in particular in the sector of public works construction. The following section focuses on the actions promoted in Greece.

\section{European Strategy on BIM-What's Happening in Greece?}

\subsection{European Strategy about BIM}

As noted, the exploitation of BIM was established in Europe with Directive 2014/24/EU. According to this directive [7], the European Parliament established a working group (EUBIM Task Group) aiming at the treatment of two pilot applications: (a) an application aiming to the construction of new buildings and (b) an application aimed at the maintenance of existing buildings. After the completion of the group's work (June 2018), the European Parliament advanced the pilot application of BIM to three parliamentary buildings for the total of the parliament buildings to be included in the application within qo years.

Through the above pilot application, it is shown that the public authorities play an important role in the promotion of the BIM use. This conclusion was reached by Cheng and Lu [26], whose research has focused on the role of public sector for BIM adoption, and Travaglini, Radujkovic and Mancini [27], who studied case studies across Europe on the role of the various stakeholders in BIM procedures. The EUBIM Task Group, as a leading European public authority group, which represents the authorities' interest regarding the digitization of the EU construction sector, is expected to play an important role in the future. The EUBIM Task Group's vision is to encourage the common use of BIM as "digital construction" in public, not just private, works with a common goal the improvement of public value for money, the quality of public real estate and the viable competitiveness of the industry. Indeed, as McAuley, Hore and West [28] underline, BIM should be firstly used in the public sector in order to promote its use in the private sector, later, through publishing specific guidelines.

The above working group compiled 4 documents-protocols that describe the BIM application procedure as follows:

- Creation Protocol: determines the creation method of a BIM for an existing building, as well as the test method for the delivered BIM.

- Project Protocol: for how the BIM is applied during the construction phase of a building.

- Maintenance Protocol: determines the way of creation of a BIM during the maintenance phase of a building.

- Charter: a management protocol that determines which information is included in the model depending on the phase of the building's life (construction or maintenance).

These documents are public European documents and, therefore, available for consultation. The EUBIM Task Group has also created the "Handbook for the introduction of building information modelling by the European Public Sector" [29], in which the basic guidelines and the experience and the relative action of other countries (United Kingdom, France, Germany, Sweden, etc.) are given. 
Finally, it should also be underlined that in some countries, not only in Europe but also elsewhere, many organizations recognize BIM's value-adding potential and thus guidelines and reports dedicated to define and explore the requirements and deliverables of BIM (Table 1).

Table 1. An indicative list of publicly available guides and reports related to BIM. Source: [11].

\begin{tabular}{|c|c|c|c|c|}
\hline Country & Organization & Project & Type and Date & $\begin{array}{l}\text { Brief Description } \\
\text { A guide made of } 4 \text { components: }\end{array}$ \\
\hline Denmark & BIPS & $\begin{array}{c}\text { Digital } \\
\text { Construction }\end{array}$ & $\begin{array}{l}\text { Guidelines-2007 } \\
\text { in } 4 \text { parts }\end{array}$ & $\begin{array}{l}\text { 3D CAD Manual, 3D Working } \\
\text { Method, Project Agreement and } \\
\text { Layer and Object Structures }\end{array}$ \\
\hline Finland & SENATE Properties & $\begin{array}{l}\text { BIM Requirements } \\
2007\end{array}$ & $\begin{array}{l}\text { Guidelines-2007 } \\
\text { in } 9 \text { volumes } \\
\text { subdivided by } \\
\text { discipline }\end{array}$ & $\begin{array}{l}\text { General operational procedures in } \\
\text { BIM projects and detailed general } \\
\text { requirements of BIM-focuses on } \\
\text { the design phase }\end{array}$ \\
\hline Netherlands & TNO & E-BOUW & $\begin{array}{l}\text { Framework-2008 } \\
\text { presented through } \\
\text { a wiki }\end{array}$ & $\begin{array}{l}\text { "A BIM Framework consisting of } \\
\text { seventeen orthogonal Dimensions } \\
\text { that describe in general the } \\
\text { Building Information Modelling } \\
\text { world constituting a "Way of } \\
\text { Thinking" about BIM }\end{array}$ \\
\hline Norway & STATSBYGG & HITOS & $\begin{array}{l}\text { Documented Pilot. } \\
\text { Sections based on } \\
\text { modelling roles }\end{array}$ & $\begin{array}{l}\text { A 'full-scale IFC test' } \\
\text { documenting experiences gained } \\
\text { on a collaborative project }\end{array}$ \\
\hline
\end{tabular}

\subsection{The Situation in Greece}

BIM makes the planning, construction and operation procedures more effective since it delimits errors, cost and time line excess and a distinct image of the quality of the construction element is depicted before and during the whole construction process [29]. These benefits are expected to contribute to the activation of the Greek construction sector, which was considerably moderated during the crisis [30]. Their maximization is expected with the establishment of the mandatory character of BIM exploitation that will arise from the directive's integration in Greek legislation. However, because of the particularities of construction activity in Greece not necessarily being met in the rest of Europe, the integration of BIM must take place with respective adaptations. In short, these particularities are the following:

- Organized construction, which constituted the axis of social residence in industrially developed countries, was replaced in Greece by private initiative (in 1950 the product of state activity in residence production represented $9.3 \%$, in 1960 the percentage fell to $1.8 \%$ and in 1970 to $1.5 \%$ ), with the phenomenon of contractual consideration operating as the basic construction and development means in cities like Athens and Piraeus [31]. This way Greek cities' development contributed to the exploitation of personal forces and savings of various social groups, which thus achieved the title of small owner and the standard of consumption of the bourgeois classes, which led, on the one hand, to a wide multiformity, and on the other to informal construction activity, a phenomenon which began in the 1950s [32] and took such considerable dimensions that in some cases we can talk about whole informal settlements [33]. Informal construction of all types was integrated in the housing sector and the state-town planning, housing and financial-policy of the country. At the same time, the state for many decades "accepted" and integrated informal constructions to the official urban web $[34,35]$.

- The state of the small owner, which survives even today, had as a result the creation of a large number of small contractors who support construction activity. This fact does not support the development of rules of construction standardization but reinforces personal construction activity.

- The construction sector constituted one of the most basic growth branches of the Greek economy, and is expected to be an important pylon of recovery of the Greek economy, in the period after the crisis, since a series of professionals (the majority organized in small scale businesses, as noted before) depend on it. Indeed, in the period before the crisis (2008), the share of the narrow 
nucleus of construction in Greek GDP had been formed close to the average of EU-28, a bit higher than France, Italy and Germany (Figure 2). During the first five years of the crisis (2008-2013) an important fall was recorded in construction activity, since on 2013, construction was 3.5 percentage points (in GDP participation terms) lower than the average EU-28. Since 2017, a small gradual increase has been noted in construction activity taking into consideration the number of construction licenses issued per year (Figure 2). This tendency permits the prediction of an increase in construction activity and the application of BIM seems to be the medium for saving time and cost for the realization and management of construction.

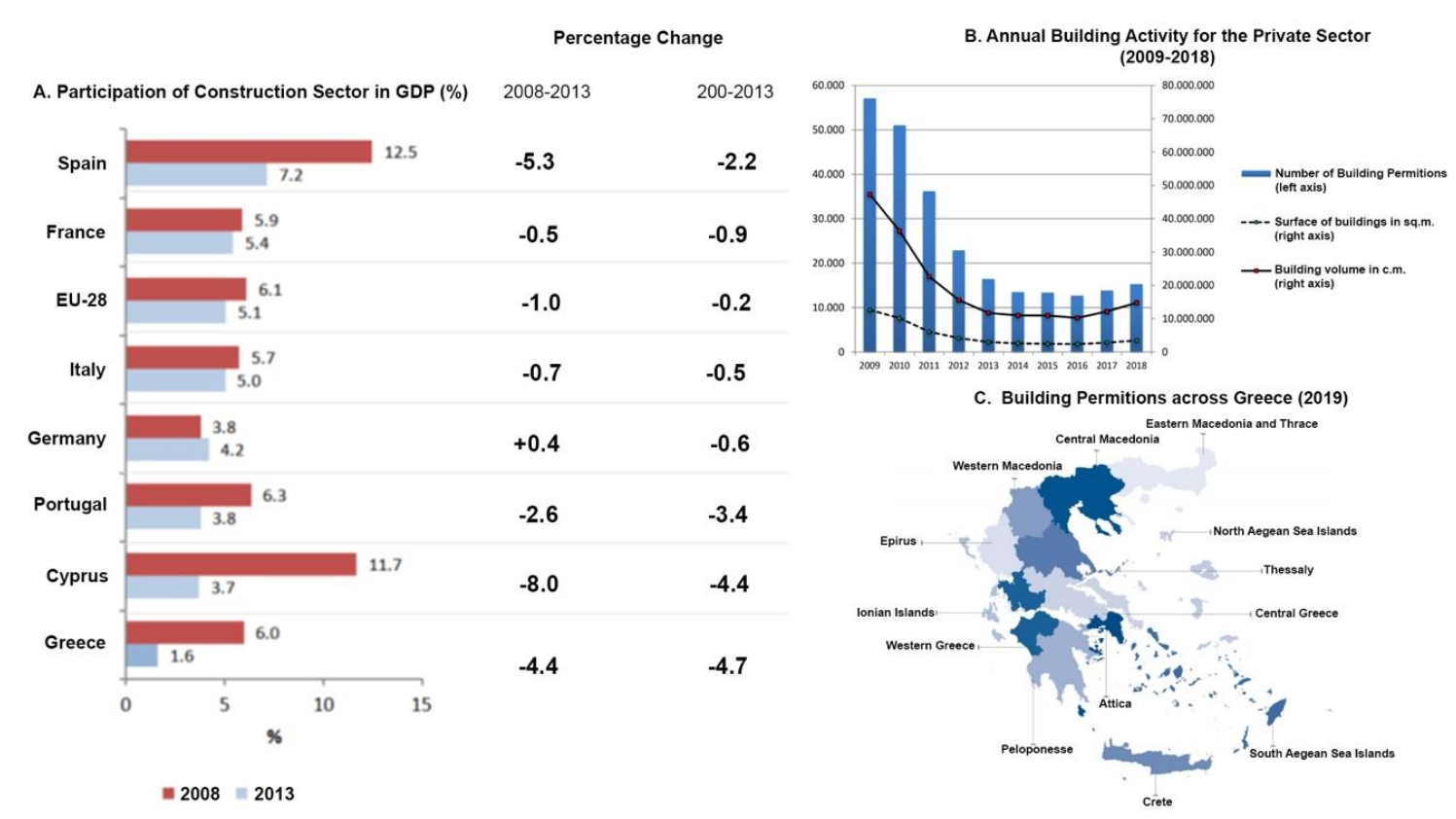

Figure 2. Statistics concerning building activity in Greece. Source: [36,37].

Currently, the issue of BIM is limited to the representation of Greece to the EUBIM Task Group with two members: A representative of the Ministry of Environment and Energy and a representative of the Technical Chamber of Greece (TCG). Indeed, the only application of BIM that has taken place at a national level was for the Stavros Niarchos Foundation (Figure 3). This pilot application was developed on a 3D model before the construction process started. However, it was not used and the conventional approach was preferred. 


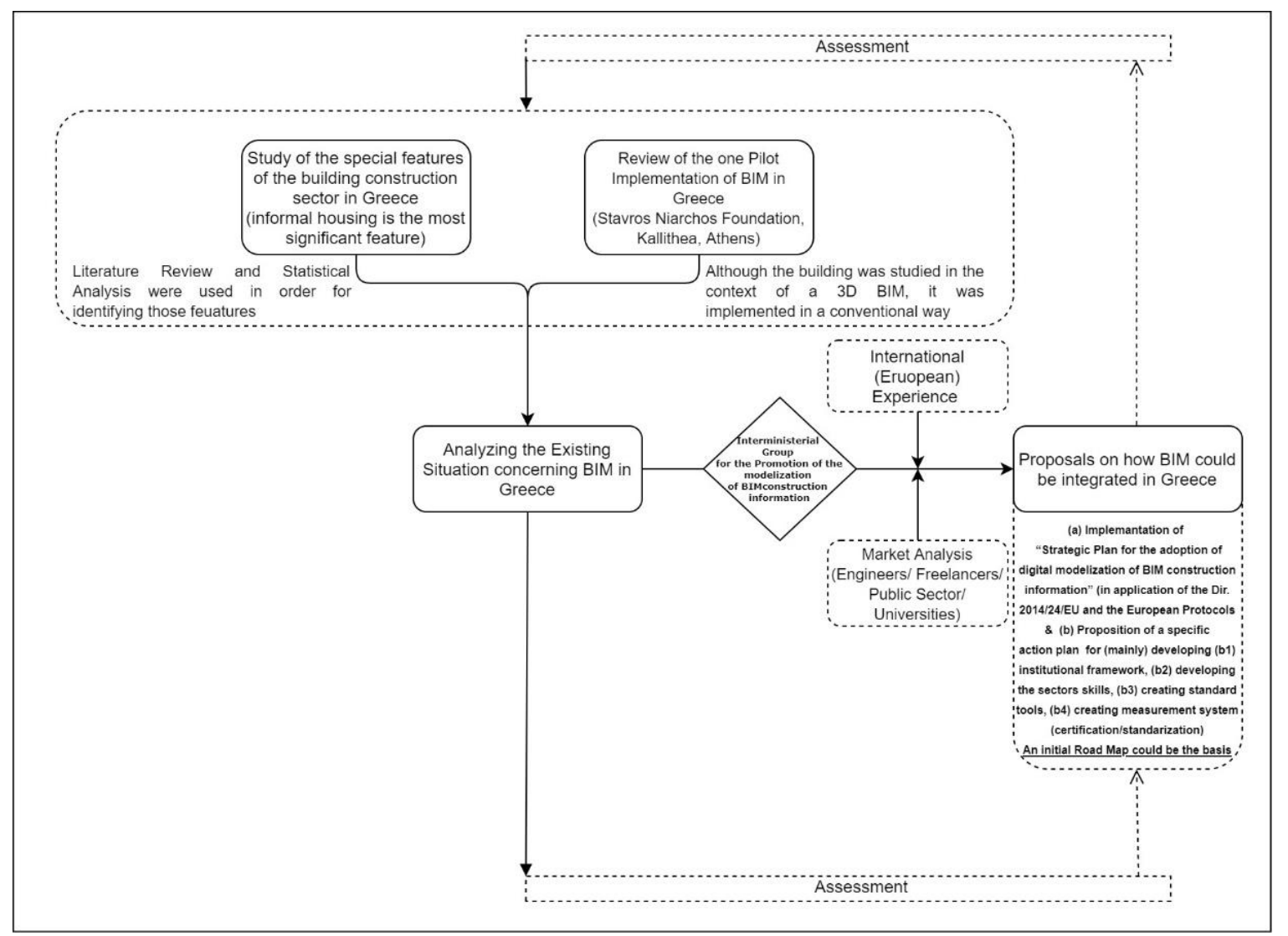

Figure 3. Research design and methodology based on the official procedures for the integration of building information modelling (BIM) in Greece. Source: own elaboration.

In order to reinforce interest in the use of BIM, the Ministry of Environment and Energy undertook the initiative to establish an "Interministerial Group for the Promotion of the modelization of BIM construction information". This initiative aims to: (a) the reinforcement of Greece in the EUBIM Task Group with the composition of the "BIM Promotion Group" (up to 5 members in total according to the European specifications) and (b) the relative common coordinated action undertaking.

The Task Group's work includes: (a) the compilation of a "Strategic Plan for the adoption of digital modelization of BIM construction information" in application of the Directive 2014/24/EE and the European Protocols and (b) the proposition of a specific action plan in order to take the necessary steps for: the creation of an institutional framework for new constructions and the maintenance of the existing ones, the development of the sector skills, the creation of standard tools (for the scholars, the constructors, the suppliers and the public sector), the standardization and certification, the creation of a measurement system for the period of data introduction, the solution of relative legal issues, the proposition for targeted financing tools, and the promotion of case studies and pilot projects.

This working group, comprising the general secretaries of the ministries and the representative of the TCG, undertakes the promotion and integration of BIM. Then, sub-working groups will be created with executives from other ministries, the professional associations and authorities, in order to represent all the stakeholders in the construction sector. The whole venture will also be supported by academic institutions, institutes and innovation bodies.

Today, the working group is focused on the development of the first roadmap, given the European protocols, the directions of the EUBIM Task Group, as well as the strategic planning examples of other European countries. The target-groups on which the adoption and integration of the BIM is aimed are the following: 
- Public sector: contracting authority (study - project), owner (operation and maintenance), public executives (policy, regulations, standards, control and certification procedures development);

- Private sector: scholars, contractors, constructors, suppliers, owners, enterprises;

- Educational bodies: academic institutes, chambers, associations, Training Institute of National Centre for Public Administration and Local Government (EKDDA), private education bodies.

The initial roadmap includes the following:

- Determination of a strategic action plan for the development of 3-5 BIM maturity phases and coordination of the sub-working groups that will operate in various ministries.

- Development of the national legal framework, which harmonizes the European framework and strategies and will provide, among others, regulation of legal issues (e.g. policy for the management of public data and common data), creation of national BIM certification and its standardisation (International Organization for Standardization - ISO, European Committee for Standardaization - CEN, etc.), open data standards and classification as well as directions for future update of the produced models.

- Assignment of management and update of data per project category.

- Creation of an evaluation system of the adjustment on regulations, supplies and contracts level, aiming to the readiness of their revision and update in relation to the policies and the legislation of the EU.

- Measurement of integration of the tool with realization initially of pilot projects, execution of case studies where the collection and evaluation will be executed in parallel.

- Creation of a stakeholders network and marketing strategies development aiming to the update of the interested parties and the diffusion of information.

- Integration of the BIM in education since it is promoted in the academic program studies to relative faculties and in various seminars for engineers in cooperation with the Technical Chamber of Greece, the chambers and the professional societies.

- Promotion of financing tools.

For the application of the above points, the task group decided the realization of three early actions (Figure 4). The first refers to the development of a strategic plan, namely, the organization of the method to carry out what is described in the initial roadmap. For the attainment of the goals (Figure 4), it is necessary to develop an adequate timetable, namely, of the sub-working groups that will occupy themselves with the more specific issues on a case-by-case basis. The second action focuses on the review of the existing legislation that governs the construction sector, recording the proposed legal actions, the update of professional registries and the creation of proper certificates for each authority. This second action actually constitutes the more essential action for the promotion of BIM in the construction sector in Greece. Finally, the third action refers to the diffusion of knowledge regarding $\mathrm{BIM}$ and the benefits arising from its use. The parameter of briefing the interested parties constitutes a crucial issue, which needs time for the desired results to be achieved. For this reason, a series of briefing actions is proposed including conventional tools like workshops and innovative tools like the development of a web-site and consultation web-platform. Such a mixed approach is a normal tactic in public briefing strategies, as concluded by case studies for the promotion of sustainable mobility and participatory planning $[38,39]$. 


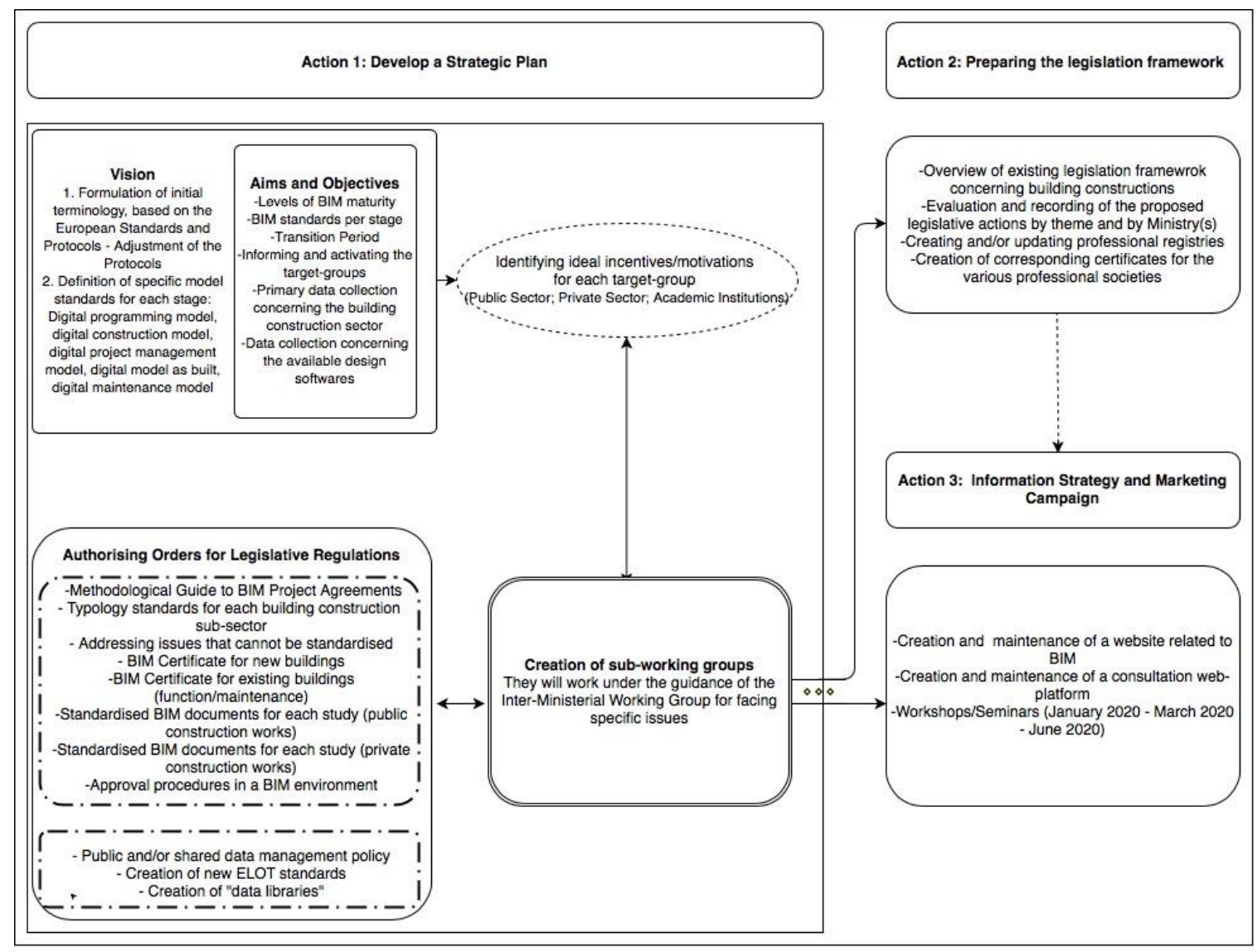

Figure 4. Actions proposed in order for the initial roadmap to be implemented. Source: Own elaboration.

\subsection{Discussion: Are All These Actions Necessary?}

It is clear from the above that the integration of BIM can, in a short time, save time and money in the construction sector but also in the public sector, as much in the construction phase as in the maintenance period where there will be a possibility of full and safe observance of all the procedures.

It is also clear that as the BIM integration will take place in a very short time in a mandatory way, through the harmonization of the European legislation to Greek law, the construction sector must be preserved, given its crucial importance for the economic life of the country but also the synergies located between a plethora of sectors, e.g., engineering, contracting, small professionals, etc. On the new digital period that has already began, the "shock" from the transition of 2D design of studies to studies in the BIM environment will be much stronger from the time that design by hand was replaced by design through computers. The Greek market will have two generations of engineers: on the one hand, the older ones, who respond to traditional techniques exploiting digital tools and, on the other, the new generation of engineers who will be directly accustomed, through the actions presented above, to a more standardized procedure and production of the construction elements. Also in the first generation, however, the presented action plan will try to mitigate the gap and promote BIM in the Greek labor market. At the same time, important issues are the confrontation of problems referring to objects not standardized as well as the simplification of control procedures, approvals and payments, an issue, which is being examined, also, already from this initial stage.

As a result, the above actions seem to be necessary since they develop the first management mechanism of this new challenge. The ministries (must) play a crucial supportive role, reinforcing the synergies that result from the above action plan, for the venture to be successful. 


\section{Conclusions}

The BIM process puts greater attention on activities around data and information management than the traditional approach to construction projects. In an era of digitization, there are many possibilities for collecting and processing data by using databases. Such capabilities change the way engineers - both freelances and employees in the various public bodies-manage each building not as an autonomous unit but also a set of buildings consisting an urban unit and a neighborhood or even a city. Indeed, through the collection of information about the structural and technical characteristics of a building it is possible to manage the building in a better way and, at the same time, to promote a more flexible urban planning scheme. The outcome could be better in case such information relates with cadastral data; the planning procedure could be simplified and the United Nations Sustainable Development Goals (SDG) can be promoted (i.e., the first SDG for eliminating extreme poverty, by giving the ability to people to utilize their ownership).

These could be only some of the positive aspects resulting from the adoption of BIM in building construction procedures. The most immediate benefits are related to each building and more specifically to the construction and management process, which is presented in this paper. So far, the experience of using such tools across Europe is positive. For that reason, the EUBIM Task Group has been set up. Its goal is to encourage the BIM use as a "digital construction" for each public and private buildings and construction project, at a European level. Four protocols were developed by this working group. Such protocols in combination with the Directive 2014/24/EU constitute the European framework for BIM.

The BIM issue has not been promoted significantly in Greece, so far. A working group has been set up at a ministry level and the TCG. This group not only represents Greece in the meeting of the EUBIM Task Group but also it is responsible for promoting BIM across the country. An initial roadmap was developed; it is expected to be implemented by conducting three main actions that play a coordinating role. As mentioned above, these actions are focused on: (a) developing an appropriate organization chart and identifying the appropriate people representing each body, (b) preparing the planned institutional framework which is going to integrate the European directions, and (c) developing public awareness. As regards this last pillar, academic bodies of the country play a significant role and so do professional bodies because of the fact that BIM is useful not only for the public sector but also the private sector. It is worth noting that those actions are necessary for promoting BIM. In a managerial level, ministries seems to share the responsibility in order for BIM to be promoted during coming years. The immediate goal is to develop pilot applications for public buildings, as was the case of the buildings of the European Parliament. The international experience could be utilized in order for BIM to be applied as a design tool and a means of promoting SDGs at a national level.

Author Contributions: Literature and Legislation review, K.P.; writing-original draft preparation, K.P., C.K.; writing-review and editing, E.B., C.K.; C.P., visualization, C.K.; supervision, E.B. All authors have read and agreed to the published version of the manuscript.

Conflicts of Interest: The authors declare no conflict of interest.

\section{References}

1. European Commission. Available online: https://ec.europa.eu/growth/content/european-construction-sectorglobal-partner-0_en (accessed on 12 January 2020).

2. Rosak-Szyrocka, J.; Janik, C. The quality aspect of management in the construction sector. Zesz. Nauk. Qual. Prod. Improv. 2017, 1, 142-151. [CrossRef]

3. OPENEXP. Available online: https://www.openexp.eu/sites/default/files/publication/files/Reports/energy_ transition_of_the_eu_building_stock_full_report.pdf (accessed on 12 January 2020).

4. STATISTA. Available online: https://www.statista.com/statistics/763219/total-employed-persons-in-buildingconstruction-industry-eu/ (accessed on 12 January 2020).

5. Huovila, P. Buildings and Climate Change: Status, Challenges, and Opportunities. UNEP, 2007. Available online: https://pdfs.semanticscholar.org/8da6/7d13e4841b680d213497073fee9a0aaf1eb5.pdf?_ga=2.135466809. 906718354.1581806291-747859432.1581679271 (accessed on 12 January 2020). 
6. Kalz, D.; Pfafferott, J. Thermal Comfort and Energy-Efficient Cooling of Nonresidential Buildings; Springer: Frieburg/Offenburg, Germany, 2014.

7. EUR-lex. Available online: https://eur-lex.europa.eu/legal-content/EN/TXT/?uri=celex\%3A32014L0024 (accessed on 12 January 2020).

8. Tranchant, A.; Beladjine, D.; Beddiar, K. BIM in French SMES: From Innovation to Necessity. In Building Information Modelling (BIM) in Design, Construction and Operations II; Galiano-Garrigos, A., Mahdjoubi, L., Brebbia, C.A., Eds.; WIT Press: Southampton, UK, 2017; pp. 135-142.

9. Pavelka, K.; Matsouskova, E.; Pavelka, K., Jr. The contribution of geomatic technologies to BIM. In Proceedings of the Capacity Building and Education Outreach in Advance Geospatial Technologies and Land Management, Dhulikhel, Nepal, 10-11 December 2019.

10. Rokooei, S. Building Information Modelling in project management: Necessities, Challenges and Outcomes, 4th International Conference on Leadership, Technology, Innovation and Business Management. Procedia Soc. Behav. Sci. 2015, 210, 87-95. [CrossRef]

11. Succar, B. Building Information Modelling framework: A research and delivery foundation for industry stakeholders. Autom. Constr. 2009, 18, 357-375. [CrossRef]

12. Davies, R.; Crespin-Mazet, F.; Limne, A.; Pardo, C.; Havenvid, M.I.; Harty, C.; Ivory, C.; Salle, R. BIM in Europe: Innovation networks in the construction sectors of Sweeden, France and the UK. In Proceedings of the 31st Annual ARCOM Conference; Raiden, A.B., Aboagye-Nimo, E., Eds.; Association of Researchers in Construction Management: Lincoln, UK, 2015; pp. 1135-1144.

13. Onur, A.Z.; Nouban, F. BIM Software in Architectural Modeling. Int. J. Innov. Technol. Explor. Eng. 2019, 8, 2089-2093.

14. McGraw-Hill Construction. Available online: http://mddb.apec.org/Documents/2013/SCSC/WKSP5/13_Scsc_ wksp5_007.pdf (accessed on 12 January 2020).

15. Lin, P.H.; Chang, C.C.; Lin, Y.H.; Lin, W.L. Green BIM Assessment Applying for Energy Consumption and Comfort in the Traditional Public Market: A case study. Sustainability 2019, 11, 4636. [CrossRef]

16. Woo, J.H. BIM and pedagogical challenges. In Proceedings of the 43rd ASC National Annual Conference, Flagstaff, AZ, USA, 12-14 April 2006.

17. Ustinovičius, L.; Rasiulis, R.; Nazarko, L.; Vilutienè, T.; Reizgevicius, M. Innovative research projects in the field of building lifecycle management. Procedia Eng. 2015, 122, 166-171. [CrossRef]

18. Jung, Y.; Joo, M. Building Information Modelling (BIM) framework for practical implementation. Autom. Constr. 2011, 20, 126-133. [CrossRef]

19. Wong, K.; Fam, Q. Building Information Modelling (BIM) for sustainable building design. Facilities 2013, 31 , 138-157. [CrossRef]

20. Volk, R.; Stengel, J.; Schultmann, F. BIM for existing buildings-literature review and future needs. Autom. Constr. 2014, 38, 109-127. [CrossRef]

21. Dzambazova, T.; Demchak, G.; Krygiel, E. Mastering: Revit Architecture 2008; Wiley Publishing, Inc.: Indianapolis, IN, USA, 2008.

22. Lu, N.; Korman, T. Implementation of BIM in modular construction: Benefits and challenges. In Construction Research Congress 2010: Innovation for Reshaping Construction Practice; Ruqanpura, J., Mohamed, Y., Lee, S.H., Eds.; American Society of Civil Enginners: Reston, VA, USA, 2010; pp. 1136-1145.

23. Events Building Green. Available online: http://events.buildinggreen.gr/wp-content/uploads/2019/11/\%CE\% 9A $\% \mathrm{CE} \% \mathrm{BF} \% \mathrm{CF} \% 81 \% \mathrm{CE} \% \mathrm{BF} \% \mathrm{CE} \% \mathrm{~B} 2 \% \mathrm{CE} \% \mathrm{AD} \% \mathrm{CF} \% 83 \% \mathrm{CE} \% \mathrm{~B} 7$. pdf (accessed on 13 January 2020).

24. Lu, Y.; Wu, Z.; Chang, R.; Li, Y. Building Information Modeling (BIM) for green buildings: A critical review and future directions. Autom. Constr. 2017, 83, 134-148. [CrossRef]

25. Ayman, R.; Alwan, Z.; McIntyre, L. BIM for sustainable project delivery: Review paper and future development areas. Archit. Sci. Rev. 2019, 1-19. [CrossRef]

26. Cheng, J.; Lu, Q. A review of the efforts and roles of the public sector for BIM adoption worldwide. J. Inf. Technol. Constr. 2015, 20, 442-478.

27. Travaglini, A.; Radujkovic, M.; Mancini, M. Building Information Modelling (BIM) and Project Management: A stakeholders perspective. Organ. Technol. Manag. Constr. Int. J. 2014, 6, 1001-1008. [CrossRef]

28. McAuley, B.; Hore, A.; West, R. Implementing Building Information Modeling in Public Works Projects in Ireland. In Proceedings of the 9th European Conference on Product and Process Modeling, Reykjiavik, Iceland, 25-27 June 2012. 
29. EUBIM Task Group. Available online: http://www.eubim.eu/wp-content/uploads/2017/07/EUBIM_ Handbook_Web_Optimized-1.pdf (accessed on 13 January 2020).

30. Bakogiannis, E.; Siti, M.; Kyriakidis, C.; Christodoulopoulou, G.; Vassi, A. Tools and Technologies for Enhancing Public Engagement in Sustainable Urban Mobility Planning-The Case Study of Rethymno, Crete; Stratigea, A., Kavroudakis, D., Eds.; Springer: Cham, Switzerland, 2019; pp. 237-256.

31. Christodoulopoulou, G.; Kyriakidis, C. Combined Urban and Traffic Planning for Sustainable Mobility in the Municiaplity of Piraeus. 2014. Available online: https://www.citybranding.gr/2014/12/blog-post_9.html (accessed on 3 February 2020).

32. Ioannidis, C.; Psaltis, C.; Potsiou, C. Suburban informal building control. Tech. Chron. Sci. J. TGC 2008, 1, 111-123.

33. Bakogiannis, E.; Kyriakidis, C.; Siti, M.; Christopoulos, K. Sustainable Urban Mobility Plans to Sustainable Isand Mobility Plans-Sustainable Mobility Policies in Island Cities. In Proceedings of the International Conference on Traffic and Transport. Engineering, Belgrade, Serbia, 27-28 September 2018.

34. Apostolopoulos, K.; Mittas, G.; Retsas, K.; Ioannidis, C.; Potsiou, C. Assessment of the legislation framework of informal development in Greece. In Proceedings of the GeoPreVi 2017, Bucharest, Romania, 14-16 September 2017.

35. Apostolopoulos, K.; Mittas, G.; Potsiou, C. Informal real estate in Greece: Assessment of the formalization framework. In Proceedings of the FIG Commission 3 Workshop and Annual Meeting 2017, Lisbon, Portugal, 27-30 November 2017.

36. Foundation for Economic and Industrial Research. Available online: http://iobe.gr/docs/research/res_05_f_ 31032015_rep_gr.pdf (accessed on 4 February 2020).

37. Hellenic Statistical Authority. Available online: https://www.statistics.gr/documents/20181/613ff01b-dcd85b2c-9c17-6751e8d17df0 (accessed on 4 February 2020).

38. Delitheou, V.; Bakogiannis, E.; Kyriakidis, C. Urban planning: Integrating smart applications to promote community engagement. Heliyon 2019, 5, e01672. [CrossRef] [PubMed]

39. Technical Chamber of Greece. Available online: http://portal.tee.gr/portal/page/portal/INFO_TEE/INFO_ 2019/10_19/NEWSLETTER20191021.pdf (accessed on 14 January 2020).

(C) 2020 by the authors. Licensee MDPI, Basel, Switzerland. This article is an open access article distributed under the terms and conditions of the Creative Commons Attribution (CC BY) license (http://creativecommons.org/licenses/by/4.0/). 